\title{
Acceptance of Consumer-Oriented Health Information Technologies (CHITs): Integrating Technology Acceptance Model with Perceived Risk
}

\author{
Mudita Sinha and Leena Fukey \\ Christ University, Bangalore, India \\ Kandappan Balasubramanian, Puvaneswaran Kunasekaran, Neethiahnanthan Ari Ragavan \\ Centre for Research and Innovation in Tourism (CRiT), Taylor's University, Malaysia \\ Mohd Hafiz Hanafiah \\ Universiti Teknologi MARA, Malaysia
}

Keywords: Consumer-oriented Health Information Technologies (CHITs), consumer acceptance, Technology Acceptance Model (TAM), perceived risk

Received: April 1, 2021

\begin{abstract}
This paper is focused on understanding the growing demand for consumer-oriented health information technologies (CHITs) wearable and adult healthcare management apps. This study utilised the Technology Acceptance Model (TAM) and integrated the concept of perceived risk. The structural Equation Modelling (SEM) technique was applied to test the research hypotheses based on the 450 quantitative responses. This study confirms significant relationships between perceived usefulness, perceived ease of use, perceived risk, attitude, behavioural intention, and actual intention in using CHITs. The findings also showed no evidence to conclude that age and education influenced respondents perceived usefulness and perceived ease of the CHITs. This study incorporated the perceived risk to fill a gap in the literature and broaden the current TAM theoretical application in the public health setting. The study findings fill the health-related technology acceptance literature gap and broaden TAM's present application in the public health realm.

Povzetek: Študija CHITS - uporabniško usmerjenih zdravstvenih informacijskih tehnologij za zdravstvene aplikacije, se ukvarja $z$ analizo več lastnosti, med drugim preprostostjo uporabe, tveganjem in uporabnostjo.
\end{abstract}

\section{Introduction}

Since the early 21 st century, there have been noticeable changes in technological development in the field of healthcare. There is an increased number of wellconnected and well-informed users for information dispersal, especially in healthcare. Recently, demographic changes such as the ageing population with an increasing chronic disease mean a growing demand for health care services $[1,2]$. Moreover, healthcare services are changing due to various technological advancements [3,4]; thus, a pressing need to adopt technological innovations in the coming years. These technologies modified and changed the healthcare operational model and people's perception of how they should be treated as patients and customers $[5,6,7]$.

One of the most popular innovative adult healthcare technologies is health information technologies (HITs). HITs are defined as healthcare provider organisations' technologies in the patient care setting [5]. It deals with a broad range of technologies that store, share, and analyse patients' health information $[8,9]$. Most recent studies on HIT focus on service quality and how healthcare providers deal with patient's data handling $[7,10]$ and how its adaptation improves medical care as per commonly advertised [5,6,11]. However, studies on users' perceptions and use of HITs are limited as most of the studies focused on health care providers' perceptions rather than the end-user themselves [12,13,14].

Consumer-oriented health information technologies (CHITs) are electronic tools, including patient portals, wearable technology, and mobile apps that make health information available directly to patients and the caretakers [15]. As the CHITs can improve health management and outcomes, such benefits would increase the consumer acceptance and usage of CHITs. Shockingly, even though numerous CHITs were developed, most were rejected or abandoned for various reasons [15,16,17]. Studies found that the rejection reasons include the poor design of technology, lack of functional value, hard to use, and offering technology features that have functional ability $[18,19,20]$. It is a significant concern because the non-acceptance or nonusage behaviour means the CHITs do not benefit user well-being. Moreover, this phenomenon leads to 
inadequate knowledge of the adoption intention of users of CHITs, resulting in research gaps.

This paper's remainder provides an overview of the existing research, hypotheses propositions, the methodology used, and empirical analysis. It is followed by a discussion of the study implications, followed by the concluding remarks.

\section{Literature review}

\section{Consumer-oriented Health Information Technologies (CHIT)}

As CHITs have become much more widely available, health-oriented apps designed for patients have exploded in recent years. Wearable devices are becoming very common, defined as computers, which reside on clothes or accessories (such as eyeglasses and rings) comfortable to wear [21]. The emergence of advanced communication technology made smartphones a medium to achieve health goals through various mobile health applications [22]. Different CHITs apps were offered through the Apple Store and Google Playstore for various health concerns [23]. Recently CHITs apps and accessories such as smart bands and wristwatches became available and favoured among health-conscious consumers [24,25]. The available CHITs apps and accessories perform health monitoring, physiological activity tracking, notification, heart rate recording, and sleep and mental health monitoring [3,4,5, $15,17,24,26,27,29,30]$. A complete and detailed report can be quickly produced to help users monitor their health conditions [29]. Currently, the demand for CHITs wearable devices for health monitoring and management combined with modern aesthetics and fashion design continues to grow [27].

\section{Technology Acceptance Model (TAM)}

Ajzen [31] developed the technology acceptance model (TAM) in 1989 to understand human interaction with technology. The TAM models postulate the relationship between an individual's intention towards a specific behaviour and his actual behaviour [32,33,34,35]. TAM speculates two specific cognitive beliefs, namely perceived usefulness and perceived ease of use. Due to its adequate explanatory power and popularity, many studies utilised TAM in the technology acceptance and adoption of various information systems (IS) [36,37,38,39,40]. Although various factors affecting user acceptance of technology have been proposed and tested, the limited study focused on the consumer acceptance of CHITs. Also, most of the researchers did not consider the effect of perceived risk as a predictor.

\section{Perceived Risk}

This study explores the enabling factors adopted from the literature on consumers' adoption intention for CHITs. First, this study adopted the revised TAM model by [41] that included the risk perception dimension in the original TAM framework. This study postulated that user perceptions of CHITs' ease of use, usefulness and perceived risk were the critical factors affecting an individual's adaptation of CHITs. Perceived risk is defined as a consumer's perceptions of the adverse consequences and uncertainty associated with their action $[42,43]$. Accordingly, customers will reduce or even refuse technology usage if they subjectively perceive an injury or a loss (risk perception) while using the technology, thus making perceived risk a vital factor affecting usage behaviour [37,44]. Besides, the opportunities to engage with their health information directly over CHITs also put the users' private information at risk [45]. This paper's remainder provides an overview of the existing research, hypotheses propositions, the methodology used, and empirical analysis. It is followed by a discussion of the study implications, followed by the concluding remarks.

\section{Study hypotheses}

Numerous studies revealed a strong influence of the perceived usefulness (PU) on consumer intention and attitude towards technology usage $[26,46,47]$. Besides, Zhang et al. [48] claimed that perceived usefulness would predict adoption intention if relevant technologies fit consumers' lifestyles. The introduction of CHITs to consumers has proven difficult, and rates of technology use have been limited as various researchers reported various reasons CHITs were abandoned by consumers $[49,50,51,52,30]$. However, when consumers perceived CHITs as useful, they would be more likely to accept CHITs [52,30].

A vast number of studies show the significant effect of perceived ease of use (PEOU) on technology usage. Abdullah et al. [32] report a substantial impact of PEOU and PU on electronic commerce adoption. Furthermore, Leong et al. [53] and Sternad and Bobek [54] also show the significant effect between PEOU and PU in their technology acceptance study. In agreement with past research, various researchers claimed that ease of use is a strong determinant of perceived usefulness in adopting technological products $[50,51,30]$. When consumers believe that using CHITs is easy and effortless, they would be more likely to accept and further use CHITs [52, 30].

Meanwhile, studies found that personal anxiety or stress and having little self-confidence were the two main obstacles in adopting technologies [42]. Consumers tend to avoid risk and prefer accuracy over speed in making decisions, which, when left unsure, they will neither act nor make a decision [43]. The difficulty of interpreting the information and the perceivably risky purchase will ultimately make them choose to abandon the product rather than taking the risk [45]. Various empirical studies demonstrated the negative impact of consumers' privacy concerns on their intention to accept technology products [42,37]. In the CHITs contexts, when consumers believe CHITs perceived risk is minimal, they are more likely to adopt the technology [46].

Technology usage's intention plays a crucial role in consumer acceptance of any technology and its continuous usage. A person's intention is governed by several factors like prior experience using technology purchase capacity and goal orientation [46,55]. Thus, various researchers 


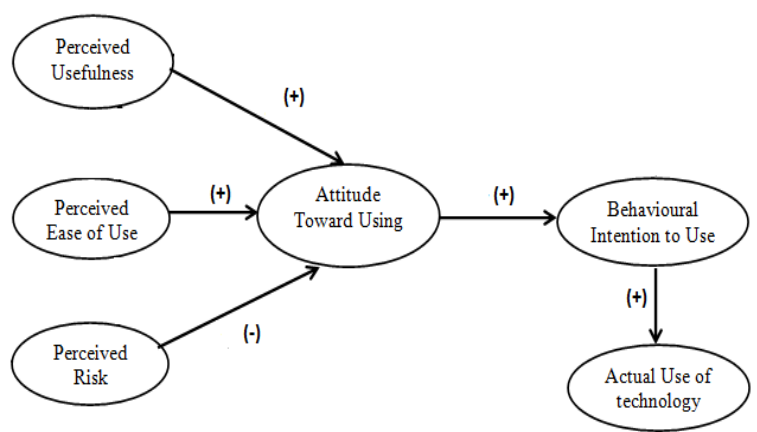

Figure 1: Revised TAM with perceived risk.

used behavioural intention to surrogate actual behaviour and were defined as consumers' intent to use the new technology or medium $[46,56]$. On the other hand, positive attitudes toward a new system resulted in solid intentions to use that system, and this relationship has been proven in the various research setting [34,48,57,58]. In the context of CHITs, when the consumers favour its usefulness, ease of use, and offer low risk, their intention to use and actual usage would increase $[52,30]$. Thus, this study hypothesised that:

$H_{1}$ : $\quad P U$ positively influences the user attitude towards using CHITs.

$\mathrm{H}_{2}$ : $\mathrm{PEOU}$ positively influences the user attitude towards using CHITs.

$H_{3}$ : Perceived risk negatively influence the user attitude towards using CHITs.

$\mathrm{H}_{4}$ : User attitude positively influences their behavioural intention to use HIT.

$H_{5}$ : Behavioural intention positively influences their actual intention to use HIT.

In line with the study hypotheses, the purpose of this study is to investigate the factors influencing consumer behaviour towards CHITs. This study empirically assesses the relationship between CHITs perceived usefulness, perceived ease of use, perceived risk and consumer attitude, behavioural intention, and actual usage. Figure 1 depicts the revised TAM model employed in the present research.

\section{Study methodology}

This study opted for the cross-sectional research design using a quantitative research survey. In the current study, a total of 22 Likert based questions adopted from Li [41] assessed the respondents' feedbacks on CHITs perceived usefulness, perceived ease of use, perceived risk and consumer attitude, behavioural intention, and actual usage. Hair et al. [59] recommended a minimum sample size of 200 for maximum likelihood estimation (MLE). Other authors also suggested larger sized samples of 400 or more would be sufficient for SEM analysis [60,61]. The choice of the respondents was established through the purposive sampling approach. In this study, the respondents were experienced users of CHITs (wearable or/and apps).

A total of 450 respondents were interviewed via the structured online questionnaire. The sample respondent's characteristics revealed that 17 percent of the respondents

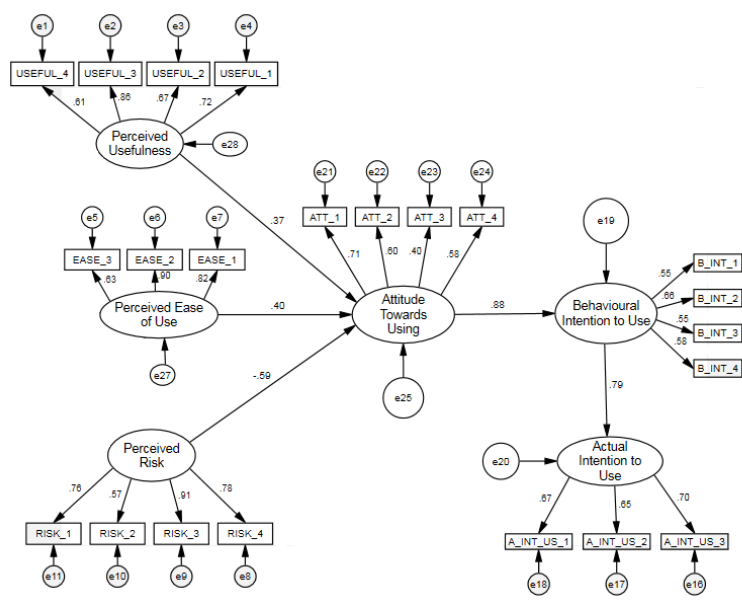

Figure 2: Structural Model Assessment.

belonged to the age group of fewer than 30 years, 59 percent were between 30 to 50 years of age, and 24 percent represented more than 50 years of age. Meanwhile, 35 percent of the respondents completed their graduation on the educational front, while 53 percent completed their post-graduation. Notably, 12 percent of the respondents were medical professionals and $\mathrm{PhD}$ holders of both science and management streams.

The data analysis was conducted using the SPSS version 24 and Analysis of Moment Structures (AMOS) statistical software.

\section{Analysis and results}

\section{Measurement Model}

Table 1 presents the relevant items, standardised loading, composite reliability, and Cronbach Alpha results through Confirmatory Factor Analysis (CFA) technique.

First, the Cronbach's alpha reliability coefficient was calculated to assess the survey instrument's reliability and psychometric properties [62]. Concerning composite reliability, most of the survey items demonstrated a greater loading value than 0.60 , indicating the research model's convergence validity. Similarly, the Cronbach alpha values of each dimension were all above 0.7 - depicting model reliability.

\section{Structural Model: Goodness-of-fit}

After confirming the measurement model reliability and validity, the defined research hypotheses were tested using the structural model technique as shown in the conceptual framework (Figure 1). Next, Figure 2 reports the structural model assessment outputs.

The model results in Table 2 yielded acceptable goodness-of-fit indices, which indicated that the model fits the observed data. The results presented were below the cut-off (accepted) values, which revealed a good fit for the present model.

Table 3 reports the path analysis result. The analysis results confirm that $\mathrm{PU}(\beta=0.371 ; \mathrm{p}<0.05)$ and $\mathrm{PEOU}$ $(\beta=0.400 ; \quad \mathrm{p}<0.05)$ had a significant (statistically) influence on attitude towards using CHITs; hence, hypothesis one and hypothesis two can be accepted. On 
the other hand, perceived risk $(\beta=-0.586 ; \mathrm{p}<0.05)$

\begin{tabular}{llll}
\hline & $\begin{array}{l}\text { Measurement } \\
\text { model }\end{array}$ & $\begin{array}{l}\text { Structural } \\
\text { model }\end{array}$ & $\begin{array}{l}\text { Threshold } \\
\text { value }\end{array}$ \\
\hline$\chi 2$ & 315.80 & 576.76 & \\
df & 194 & 243 & \\
Chi-square/df & 1.628 & 2.168 & $<3.0$ \\
$(\chi 2 /$ df $)$ & & & \\
GFI & 0.802 & 0.825 & $>0.90$ \\
AGFI & 0.842 & 0.860 & $>0.80$ \\
CFI & 0.895 & 0.857 & $>0.90$ \\
NFI & 0.872 & 0.835 & $>0.90$ \\
RMSEA & 0.080 & 0.091 & $<0.10$ \\
PCFI & 0.751 & 0.667 & $<0.50$ \\
PNFI & 0.649 & 0.559 & $<0.50$
\end{tabular}

Table 2: Goodness-of-fit and incremental indices for measurement and structural models.

significantly negatively affects consumer attitude towards using CHITs as a health caretaker. Thus, hypothesis three could be fully asserted. Furthermore, the path analysis also confirms that the attitude towards using CHITs positively and significantly $(\beta=0.211 ; \quad \mathrm{p}<0.05) \quad$ influences behavioural intention to use CHITs. Hence, hypothesis four is fully asserted. Finally, behavioural intention to use CHITs had a positive and significant $(\beta=0.786$; $p<0.05)$ impact on the behavioural intention to use CHITs, which asserted hypothesis five.

\section{Conclusion}

The study findings fill the literature gap and broaden TAM's current theoretical application in the public health realm. This study tested an extended TAM framework to consumer acceptance towards the CHITs system. This study's main contribution is the verification of consumers' attitudes, perceived risk, and behavioural intention to adopt and use CHITs. The study findings have enriched research on the relationship between technology acceptance, perceived risks and behavioural intentions, which could shed light on future research on the application of consumer acceptance theories. This study also highlights that CHIT is a promising concept to improve the personal care experience and improve population health. The finding of this study shows that smartphone is a powerful predictor of interest and usage in CHITs due to the ease of use, mobility, and connectivity of smartphones. It offers an excellent opportunity for CHITs providers to improve their mobile-based products and apps, focusing on usability and features that consumers expect.

The findings showed that perceived ease of using CHITs is more important than the aspects of perceived usefulness. Our research found that ease of use of CHITs is another critical factor that affects consumers' health information-seeking behaviour. Therefore, mobile

\begin{tabular}{|c|c|c|c|c|}
\hline Items & Loading & $\begin{array}{l}\text { Construct } \\
\text { Reliability }\end{array}$ & $\begin{array}{c}\text { Cronbach } \\
\text { Alpha }\end{array}$ & $\begin{array}{c}\text { Average } \\
\text { Variance } \\
\text { Extraction }\end{array}$ \\
\hline Perceived Usefulness & & 0.811 & 0.812 & 0.519 \\
\hline I will use the CHIT if it helps my personal health management (USEFUL_1) & 0.749 & & & \\
\hline I will use CHIT if it helps me develop healthy habits (USEFUL_2) & 0.649 & & & \\
\hline I will use the CHIT if it helps me maintain a healthy status (USEFUL_3) & 0.804 & & & \\
\hline Perceived Ease of Use & & 0.834 & 0.835 & 0.628 \\
\hline I will use the CHIT if learning to operate the technology is easy for me (EASE_1) & 0.841 & & & \\
\hline I will use the CHIT if the user interface is clear and intuitive (EASE_2) & 0.849 & & & \\
\hline I will use the CHIT if it is flexible to interact with it (EASE_3) & 0.676 & & & \\
\hline Perceived Risk & & 0.847 & 0.849 & 0.585 \\
\hline CHIT does not provide adequate protection of my personal health information (RISK_1) & 0.803 & & & \\
\hline CHIT does not protect the privacy of its users (RISK_2) & 0.607 & & & \\
\hline CHIT will share my personal health information without my authorisation (RISK_3) & 0.862 & & & \\
\hline Usage Attitude & & 0.758 & 0.763 & 0.446 \\
\hline I will use the CHIT only if I can utilise it (ATT_1) & 0.790 & & & \\
\hline I will use the CHIT if I find it rewarding to use (ATT_2) & 0.685 & & & \\
\hline I will use CHIT if it is reasonably priced (ATT_3) & 0.661 & & & \\
\hline Behavioural Intention & & 0.767 & 0.767 & 0.452 \\
\hline I prefer to use the CHIT both at home and office (B_INT_1) & 0.665 & & & \\
\hline I prefer to use CHIT if most people around are using it (B_INT_2) & 0.635 & & & \\
\hline I prefer to use CHIT if it is easy to obtain (B_INT_3) & 0.733 & & & \\
\hline Actual Intention to Use & & 0.769 & 0.770 & 0.527 \\
\hline Assuming I have access to the CHIT, I intend to use it. (A_INT_US_1) & 0.714 & & & \\
\hline Given that I have access to CHIT, I will use it more frequently (A_INT_US_2) & 0.708 & & & \\
\hline I intent to recommend the CHIT to my friends (A_INT_US_3) & 0.754 & & & \\
\hline
\end{tabular}

Table 1: Measurement model - Factor Loadings. 
healthcare providers should focus on improving the ease of use of CHITs apps and services. Nonetheless, the

\begin{tabular}{|c|c|c|c|}
\hline Hypotheses & $\begin{array}{l}\text { Standard } \\
\text { estimate }\end{array}$ & $\begin{array}{c}\text { Standard } \\
\text { error }\end{array}$ & $\mathrm{P}$-value \\
\hline $\begin{array}{l}\mathrm{H}_{1} \text { : Perceived usefulness } \\
\rightarrow \text { Attitude towards using } \\
\text { CHIT }\end{array}$ & 0.371 & 0.116 & $0.000 * * *$ \\
\hline $\begin{array}{l}\mathrm{H}_{2} \text { : Perceived ease of use } \\
\rightarrow \text { Attitude towards using } \\
\text { CHIT }\end{array}$ & 0.400 & 0.124 & $0.000 * * *$ \\
\hline $\begin{array}{l}\mathrm{H}_{3} \text { : Perceived risk } \rightarrow \\
\text { Attitude towards using } \\
\text { CHIT }\end{array}$ & -0.586 & 0.103 & $0.000 * * *$ \\
\hline $\begin{array}{l}\mathrm{H}_{4}: \text { Attitude towards using } \\
\mathrm{CHIT} \rightarrow \text { Behavioural } \\
\text { intention }\end{array}$ & 0.877 & 0.132 & $0.000 * * *$ \\
\hline $\begin{array}{l}\mathrm{H}_{5} \text { : Behavioural intention } \\
\rightarrow \text { Actual intention in } \\
\text { using CHIT }\end{array}$ & 0.786 & 0.272 & $0.000 * * *$ \\
\hline
\end{tabular}

Table 3: Path analysis.

CHITs design, ergonomic and implementation could be improved only by understanding the consumer wants and needs. On the other hand, this study also highlighted how perceived risk in CHITs influence consumer adoption and usage. It is reasonable to assume that a large number of consumers are still intimidated by CHITs. Based on the study findings, given that the perceived risks negatively impact consumers' attitudes, CHITs providers should focus more on enhancing the reliability and validity of health information provided by them.

This study also offers significant inputs to the practitioner; perceived usefulness and ease of use are factors that managers and policymaker consider before introducing health information technology. The study results highlight the need for further research by including people with various cultural identities and socioeconomic statuses, and cultural dynamics in CHITs better understand consumer acceptance of such technologies. Understanding the factors affecting the acceptance of CHITs as personal health caretakers is necessary to ensure a sustainable adoption, which would result in people's continuous dependence on human health caretakers in the future. Future research should test more complex predictive models and add other consumer behavioural attributes and preferences to optimise CHITs acceptance and usage further. This idea also aligns with SDG nine, which to enhance technological capabilities among the world population to achieve community well-being.

\section{Acknowledgement}

The authors confirm that there is no conflict of interest to declare for this publication.

\section{References}

[1] Dall, T. M., Gallo, P. D., Chakrabarti, R., West, T., Semilla, A. P., \& Storm, M. V. (2013). An aging population and growing disease burden will require alarge and specialised health care workforce by 2025 . Health Affairs, 32(11), 2013-2020. https://doi.org/10.1377/hlthaff.2013.0714

[2] Etkind, S., Bone, A., Gomes, B., Lovell, N., Evans, C., Higginson, I., \& Murtagh, F. (2017). How many people will need palliative care in 2040? Past trends, future projections and implications for services. $B M C$ Medicine, 15(1), 1-10. https://doi.org/10.1186/s12916-017-0860-2

[3] Ahamed, F., Palepu, S., Dubey, M., \& Nongkynrih, B. (2017). Scope of mobile health in Indian health care system-the way forward. International Journal of Community Medicine and Public Health, 4, 875881. https://doi.org/10.18203/2394-6040. ijcmph20171300

[4] Bernstein, M. L., McCreless, T., \& Cote, M. J. (2007). Five constants of information technology adoption in healthcare. Hospital Topics, 85(1), 17-25. https://doi.org/10.3200/HTPS.85.1.17-26

[5] Dias, D., \& Paulo Silva Cunha, J. (2018). Wearable health devices - vital sign monitoring, systems and technologies. Sensors, 18(8), 2414. https://doi.org/10.3390/s18082414

[6] Latif, S., Qadir, J., Farooq, S., \& Imran, M. A. (2017). How $5 \mathrm{~g}$ wireless (and concomitant technologies) will revolutionise healthcare? Future Internet, 9(4), 93. https://doi.org/10.3390/fi9040093

[7] Majumder, S., Aghayi, E., Noferesti, M., Memarzadeh-Tehran, H., Mondal, T., Pang, Z., \& Deen, M. J. (2017). Smart homes for elderly healthcare-Recent advances and research challenges. Sensors, 17(11), 2496. https://doi.org/10.3390/s17112496

[8] Jeong, I., Bychkov, D., \& Searson, P. C. (2018). Wearable devices for precision medicine and health state monitoring. IEEE Transactions on Biomedical Engineering, 66(5), 1242-1258. https://doi.org/10.1109/TBME.2018.2871638

[9] Kundu, N., Rani, G., \& Dhaka, V. S. (2020). Machine Learning and IoT based Disease Predictor and Alert Generator System. Paper presented at the 2020 Fourth International Conference on Computing Methodologies and Communication (ICCMC). https://doi.org/10.1109/ICCMC48092.2020.ICCMC000142

[10] Kisekka, V., \& Giboney, J. S. (2018). The effectiveness of health care information technologies: evaluation of trust, security beliefs, and privacy as determinants of health care outcomes. Journal of Medical Internet Research, 20(4), e107. https://doi.org/10.2196/jmir.9014

[11] Wager, K. A., Lee, F. W., \& Glaser, J. P. (2017). Health care information systems: A practical approach for health care management: John Wiley \& Sons.

[12] Degenholtz, H. B., Resnick, A., Lin, M., \& Handler, S. (2016). Development of an applied framework for understanding health information technology in 
nursing homes. Journal of the American Medical Directors Association, 17(5), 434-440. https://doi.org/10.1016/j.jamda.2016.02.002

[13] Gardner, R. L., Cooper, E., Haskell, J., Harris, D. A., Poplau, S., Kroth, P. J., \& Linzer, M. (2019). Physician stress and burnout: the impact of health information technology. Journal of the American Medical Informatics Association, 26(2), 106-114. https://doi.org/10.1093/jamia/ocy145

[14]Zallman, L., Finnegan, K., Roll, D., Todaro, M., Oneiz, R., \& Sayah, A. (2018). Impact of medical scribes in primary care on productivity, face-to-face time, and patient comfort. The Journal of the American Board of Family Medicine, 31(4), 612-619. https://doi.org/10.3122/jabfm.2018.04.170325

[15] Cheung, M.L., Chau, K.Y., Lam, M.H.S., Tse, G., Ho, K.Y., Flint, S.W., Broom, D.R., Tso, E.K.H. and Lee, K.Y. (2019). Examining consumers' adoption of wearable healthcare technology: The role of health attributes. International Journal of Environmental Research and Public Health, 16(13), 2257. https://doi.org/10.3390/ijerph16132257

[16] Dinh-Le, C., Chuang, R., Chokshi, S., \& Mann, D. (2019). Wearable health technology and electronic health record integration: scoping review and future directions. JMIR mHealth and uHealth, 7(9), e12861. https://doi.org/10.2196/12861

[17]Li, J., Ma, Q., Chan, A. H., \& Man, S. (2019). Health monitoring through wearable technologies for older adults: Smart wearables acceptance model. Applied Ergonomics, 75, 162-169. https://doi.org/10.1016/j.apergo.2018.10.006

[18] Cilliers, L. (2020). Wearable devices in healthcare: Privacy and information security issues. Health Information Management Journal, 49(2-3), 150-156. https://doi.org/10.1177/1833358319851684

[19] Kuziemsky, C., Randell, R., \& Borycki, E. (2016). Understanding Unintended Consequences and Health Information Technology: Contribution from the IMIA Organizational and Social Issues Working Group. Yearbook of Medical Informatics (1), 53. https://doi.org/10.15265/IY-2016-027

[20] Sillence, E., Briggs, P., \& Harris, P. R. (2018). Revisiting the Issue of Trust in E-Health. In WebBased Behavioral Therapies for Mental Disorders (pp. 241-259): IGI Global. https://doi.org/10.4018/978-1-5225-3241-5.ch009

[21]Li, H., Wu, J., Gao, Y., \& Shi, Y. (2016). Examining individuals' adoption of healthcare wearable devices: An empirical study from privacy calculus perspective. International Journal of Medical Informatics, 88, 8-17. https://doi.org/10.1016/j.ijmedinf.2015.12.010

[22] Shen, C., Wang, M.P., Chu, J.T., Wan, A., Viswanath, K., Chan, S.S.C., \& Lam, T.H. (2017). Health app possession among smartphone or tablet owners in Hong Kong: Population-based survey. Advanceing Digital Health \& Open Science, 5(6). https://doi.org/10.2196/mhealth.7628

[23] Krishnan, G., \& Selvam, G. (2019). Factors influencing the download of mobile health apps:
Content review-led regression analysis. Health Policy and Technology, 8(4), 356-364

https://doi.org/10.1016/j.hlpt.2019.09.001

[24] Sun, J., \& Liu, Y. (2020). Using Smart Bracelets to Assess Heart Rate Among Students During Physical Education Lessons: Feasibility, Reliability, and Validity Study. JMIR mHealth and uHealth, 8(8), e17699. https://doi.org/10.2196/17699

[25] Vinciguerra, S., \& Vinciguerra, M. (2019). Smart devices and healthy aging. Nutrition and Healthy Aging, 5(1), 13-19. https://doi.org/10.3233/NHA-170039

[26] Gajanayake, R., Sahama, T., \& Iannella, R. (2013). The role of perceived usefulness and attitude on electronic health record acceptance. Paper presented at the 2013 IEEE 15th International Conference on eHealth Networking, Applications and Services (Healthcom 2013).

[27] Koorts, H., Salmon, J., Timperio, A., Ball, K., Macfarlane, S., Lai, S.K., Brown, H., Chappel, S.E., Lewis, M. and Ridgers, N.D. (2020). Translatability of a Wearable Technology Intervention to Increase Adolescent Physical Activity: Mixed Methods Implementation Evaluation. Journal of Medical Internet Research, 22(8), e13573. https://doi.org/10.2196/13573

[28] Somrak, M., Luštrek, M., Šušteršič, J., Krivc, T., Mlinar, A., Travnik, T., Stepan, L., Mavsar, M. and Gams, M. (2014). Tricorder: Consumer Medical Device for Discovering Common Medical Conditions. Informatica, 38(1), 81-88.

[29] Tabi, K., Randhawa, A.S., Choi, F., Mithani, Z., Albers, F., Schnieder, M., Nikoo, M., Vigo, D., Jang, K., Demlova, R. and Krausz, M. (2019). Mobile apps for medication management: review and analysis. JMIR mHealth and uHealth, 7(9), e13608. https://doi.org/10.2196/13608

[30] Wang, H., Tao, D., Yu, N., \& Qu, X. (2020). Understanding consumer acceptance of healthcare wearable devices: An integrated model of UTAUT and TTF. International Journal of Medical Informatics, 104156. https://doi.org/10.1016/j.ijmedinf.2020.104156

[31] Davis, F. D. (1989). Perceived usefulness, perceived ease of use, and user acceptance of information technology. MIS Quarterly, 319-340. https://doi.org/10.2307/249008

[32] Abdullah, F., Ward, R., \& Ahmed, E. (2016). Investigating the influence of the most commonly used external variables of TAM on students' Perceived Ease of Use (PEOU) and Perceived Usefulness (PU) of e-portfolios. Computers in Human Behavior, 63, 75-90. https://doi.org/10.1016/j.chb.2016.05.014

[33] Hong, S.H., \& Yu, J.H. (2018). Identifiation of external variables for the technology acceptance model (TAM) in the assessment of BIM application for mobile devices. IOP Conference Series: Materials Science and Engineering, 401(1), doi: 10.10881457899X/401/1/012027. 
https://doi.org/10.1088/1757-899X/401/1/012027

[34] Gjoreski, M. (2021). A Method for Combining Classical and Deep Machine Learning for Mobile Health and Behavior Monitoring. Informatica, 45(1), 169-170. https://doi.org/10.31449/inf.v45i1.3482

[35] Li, Y., Qi, J., \& Shu, H. (2008). Review of relationships among variables in TAM. Tsinghua Science \& Technology, 13(3), 273-278. https://doi.org/10.1016/S1007-0214(08)70044-0

[36] Gefen, D., \& Straub, D. (1997). Gender differences in the perception and use of e-mail: An extension to the technology acceptance model. 389-400. https://doi.org/10.2307/249720

[37] Mutahar, A. M., Daud, N. M., Ramayah, T., Isaac, O., \& Aldholay, A. H. (2018). The effect of awareness and perceived risk on the technology acceptance model (TAM): mobile banking in Yemen. International Journal of Services and Standards, 12(2), 180-204. https://doi.org/10.1504/IJSS.2018.091840

[38] Harbi, A. (2021). Health care Expert's readiness to implement National Unified Medical Records (NUMR) system in the United Arab Emirates; A Qualitative study. Informatica, 45(5), 687-696. https://doi.org/10.31449/inf.v45i5.3358.

[39] Straub, D., Keil, M., \& Brenner, W. (1997). Testing the technology acceptance model across cultures: A three country study. Information \& Management, 33(1), 1-11. https://doi.org/10.1016/S0378-7206(97)00026-8

[40] Venkatesh, V. and Davis, F.D. (2000). A theoretical extension of the technology acceptance model: four longitudinal field studies. Management Science, 46(2), 186-204. https://doi.org/10.1287/mnsc.46.2.186.11926

[41] Šumak, B., Heričko, M., Pušnik, M., \& Polančič, G. (2011). Factors affecting acceptance and use of Moodle: An empirical study based on TAM. Informatica, 35(1), 91-100.

[42] Hirunyawipada, T., \& Paswan, A. K. (2006). Consumer innovativeness and perceived risk: implications for high technology product adoption. Journal of Consumer Marketing, 23(4), 182-198. https://doi.org/10.1108/07363760610674310

[43] Im, I., Kim, Y., \& Han, H.-J. (2008). The effects of perceived risk and technology type on users' acceptance of technologies. Information \& Management, 45(1), 1-9. https://doi.org/10.1016/j.im.2007.03.005

[44] Ehrenfeld, J. M. (2017). Wannacry, cybersecurity and health information technology: A time to act. Journal of Medical Systems, 41(7), 104. https://doi.org/10.1007/s10916-017-0752-1

[45] Blanke, S. J., \& McGrady, E. (2016). When it comes to securing patient health information from breaches, your best medicine is a dose of prevention: A cybersecurity risk assessment checklist. Journal of Healthcare Risk Management, 36(1), 14-24. https://doi.org/10.1002/jhrm.21230

[46] Taufik, N., \& Hanafiah, M. H. (2019). Airport passengers' adoption behaviour towards self-check-in
Kiosk Services: the roles of perceived ease of use, perceived usefulness and need for human interaction. Heliyon, 5(12), e02960.

https://doi.org/10.1016/j.heliyon.2019.e02960

[47] Purnawirawan, N., De Pelsmacker, P., \& Dens, N. (2012). Balance and sequence in online reviews: How perceived usefulness affects attitudes and intentions. Journal of Interactive Marketing, 26(4), 244-255. https://doi.org/10.1016/j.intmar.2012.04.002

[48]Zhang, M., Luo, M., Nie, R., \& Zhang, Y. (2017). Technical attributes, health attribute, consumer attributes and their roles in adoption intention of healthcare wearable technology. International Journal of Medical Informatics, 108, 97-109. https://doi.org/10.1016/j.ijmedinf.2017.09.016

[49] Cocosila, M., \& Archer, N. (2018). Modeling consumer acceptance of electronic personal health records. Journal of Electronic Commerce Research, 19(2), 119-134.

[50] Garavand, A., Mohseni, M., Asadi, H., Etemadi, M., Moradi-Joo, M., \& Moosavi, A. (2016). Factors influencing the adoption of health information technologies: a systematic review. Electronic Physician, 8(8), 2713. https://doi.org/10.19082/2713

[51] Tao, D., Shao, F., Liu, S., Wang, T., \& Qu, X. (2016). Predicting factors of consumer acceptance of health information technologies: a systematic review. In Proceedings of the Human Factors and Ergonomics Society Annual Meeting (Vol. 60, No. 1, pp. 598-602). Sage CA: Los Angeles, CA: SAGE Publications. https://doi.org/10.1177/1541931213601137

[52] Tao, D., Wang, T., Wang, T., Zhang, T., Zhang, X., \& Qu, X. (2020). A systematic review and metaanalysis of user acceptance of consumer-oriented health information technologies. Computers in Human Behavior, 104, 106147. https://doi.org/10.1016/j.chb.2019.09.023

[53] Leong, L.Y., Ooi, K.-B., Chong, A. Y.-L., \& Lin, B. (2011). Influence of individual characteristics, perceived usefulness and ease of use on mobile entertainment adoption. International Journal of Mobile Communications, 9(4), 359-382. https://doi.org/10.1504/IJMC.2011.041141

[54] Sternad, S., \& Bobek, S. (2013). Impacts of TAMbased external factors on ERP acceptance. Procedia Technology, 9, 33-42. https://doi.org/10.1016/j.protcy.2013.12.004

[55]Zulkifly, M. I., Zahari, M. S. M., Hanafiah, M. H., Hemdi, M. A., \& Ismail, M. N. (2016). Customers' technology readiness and customer information satisfaction on tablet-based menu ordering experience. Heritage, Culture and Society, 549-553. https://doi.org/10.1201/9781315386980-97

[56] Rahman, F. B. A., Hanafiah, M. H. M., Zahari, M. S. M., \& Jipiu, L. B. (2021). Systematic Literature Review on The Evolution of Technology Acceptance and Usage Model used in Consumer Behavioural Study. International Journal of Academic Research in Business and Social Sciences, 11(13), 272-298. 
https://doi.org/10.6007/IJARBSS/v11-i13/8548

[57] Mohamad, M. A., Hanafiah, M. H., \& Radzi, S. M. (2021). Understanding tourist mobile hotel booking behaviour: Incorporating perceived enjoyment and perceived price value in the modified Technology Acceptance Model. Tourism \& Management Studies, 17(1), 19-30.

https://doi.org/10.18089/tms.2021.170102

[58] Tarhini, A., Hone, K., \& Liu, X. (2014). The effects of individual differences on e-learning users' behaviour in developing countries: A structural equation model. Computers in Human Behavior, 41, 153-163. https://doi.org/10.1016/j.chb.2014.09.020

[59] Hair, J., Black, W., Anderson, R., \& Babin, B. (2018). Multivariate Data Analysis (8, ilustra ed.). Cengage Learning EMEA.

[60] Kock, N., \& Hadaya, P. (2018). Minimum sample size estimation in PLS-SEM: The inverse square root and gamma-exponential methods. Information Systems Journal, 28(1), 227-261. https://doi.org/10.1111/isj.12131

[61] Shi, D., Lee, T., \& Maydeu-Olivares, A. (2019). Understanding the model size effect on SEM fit indices. Educational and Psychological Measurement, 79(2), 310-334. https://doi.org/10.1177/0013164418783530

[62] Nunnally, J.C. (1978). Psychometric Theory. New York: McGraw Hill. 